\title{
Education for Sustainability: Vision and Action of Higher Education for Sustainable Consumption
}

\author{
Marwa Biltagy ${ }^{1}$ \\ ${ }^{1}$ Faculty of Economics and Political Science, Cairo University, Egypt \\ Correspondence: Marwa Biltagy, Assistant Professor of Economics, Faculty of Economics and Political Science, \\ Cairo University, Egypt. E-mail: bilmarwa@feps.edu.eg
}

Received: October 27, 2015

Accepted: November 23, 2015

Online Published: November 25, 2015

doi:10.5539/ijef.v7n12p282

URL: http://dx.doi.org/10.5539/ijef.v7n12p282

\begin{abstract}
This paper provides the context around why transformative learning and deeper engagement in sustainability issues is important. The way of learning is critical in promoting the skills and motivation needed for sustainability challenges. Sustainability education should be included much more than other knowledge acquisition i.e. integrating a transformative, participatory learning process that matches up behavior with knowledge. This paper focuses on how higher education institutions can promote sustainable consumption. Higher education has an important role to play concerning education for sustainable consumption and the construction of a learning society. The results include innovative strategies to change curricula; to shape public opinion and national policies for sustainability; to make sure that research serves the needs of social and economic development that is sustainable and to enable students to develop their knowledge, values and skills that society will need for real progress towards sustainable consumption.
\end{abstract}

Keywords: education, higher education, sustainability, sustainable development, sustainable consumption

\section{Introduction}

Higher education institutions are those that conduct studies, training and research at the post-secondary level. These include public and private universities, institutions affiliated to them, other research centers and educational establishments that are approved as institutions of higher education. Higher education systems should respond to what society expects from them. Institutions of higher education must play a leading role in making the transition to sustainability. Higher education can realize sustainability through policy making, technology transfer, capacity building, science and research on its campuses. Universities can support a sustainable society by teaching and transferring knowledge through research. Despite increased awareness of the human impact on the environment and a greater focus on personal as well as global consequences of individual lifestyle choices, sustainable development and sustainable consumption are still not central topics in educational systems today (UNESCO, 1998).

Consumption choices are decisions that have remarkable impacts on natural resources, environmental protection including energy policies. These choices play a key role in climate change, since almost everything consumed demands energy (UNEP, 2011b). Higher education for sustainable consumption is a key instrument to achieve resource efficiency and low carbon lifestyles. It also gives citizens the means to influence markets and production patterns in a positive way. The crucial goal of higher education for sustainable consumption is to pass on the skills, knowledge and attitudes needed to help individuals in creating the changes required to achieve sustainability (UNESCO, 2002). Alternatively, higher education is one of the most powerful tools of providing individuals with the suitable competencies to become responsible and sustainable consumers. Consumption choices shape the patterns of markets and production. They have remarkable effects on supporting or rejecting practices of some companies, voting in the market and communicating with decision-makers. Accordingly, incorporating the concept of responsible consumption into daily actions must be modified over time in response to changes in society.

The main questions that this paper aims to answer are: What is the concept of education for sustainability? What is sustainable consumption and what is the importance that it represents? What is the relationship between higher education for sustainable consumption and higher education for sustainable development? What are the main challenges of higher education for sustainable consumption? And how to implement higher education for 
sustainable consumption? The methodology of this paper is based on studying and analyzing the topic of higher education for sustainable consumption by clarifying the concept, identifying the challenges, explaining the action plans and presenting alternative solutions.

The main challenge concerning higher education for sustainable consumption is how to support plans, agendas and programs that encourage the individual's understanding of the central role they play in providing knowledge and skills and allow them to become actors of change towards more sustainable consumption behaviors. Moreover, the process of reorienting teacher training to address sustainability is a great challenge facing higher education institutions. Higher education for sustainable consumption involves many actions, for example, providing structural frameworks and learning environments in which actions support the objectives of higher education for sustainable consumption programs and plans; presenting the efficient training to teachers; including topics and courses about education for sustainable consumption in the curricula and encouraging research in education for sustainable consumption and related topics.

\section{The Concept of Education for Sustainability}

The goal for almost all countries is to change their target from development to sustainable development. This means that, the emphasis is to widen the economic view of development to a larger vision that includes the other important components of sustainability i.e. social, economic and environmental. Knowledge-based economies call for new levels of learners, teachers and skills, while insufficient opportunities to access higher levels of learning and acquire skills are resulting in a knowledge divide among and within countries, with major economic and employment consequences. The best way to meet these huge challenges is through an ambitious, transformative and inclusive post-2015 education agenda of universal relevance applicable to all countries, irrespective of their development status. The international community has come a long way since the worldwide movement for Education for All, which was initiated in Jomtien, in 1990 and reaffirmed in Dakar in 2000. While exceptional progress has been made, the journey to achieving Education for All is not over.

The sustainable development goals (SDGs) proposed by the Open Working Group (OWG) of the General Assembly in July 2014 included a separate goal on education. The international education community, co-led by the United Nations Educational, Scientific and Cultural Organization (UNESCO) and the United Nations Children's Fund (UNICEF), began a broad and intensive consultation to define the future education agenda. This extensive process concluded in the Muscat Agreement adopted at the Global EFA Meeting in Oman in May 2014, representing a shared vision of education for the future (Sarabhai, 2015).

To define the process of education for sustainability (see figure one), some important questions should be identified, for example,

- What are the learning values and curricula that should be formulated?

- How can assessment methods support the learning process?

- What are the required educational planning and resourcing systems?

- What are the suitable approaches of learning needed for decent and sustainable work?

- What is the role of international support in achieving sustainability in education?

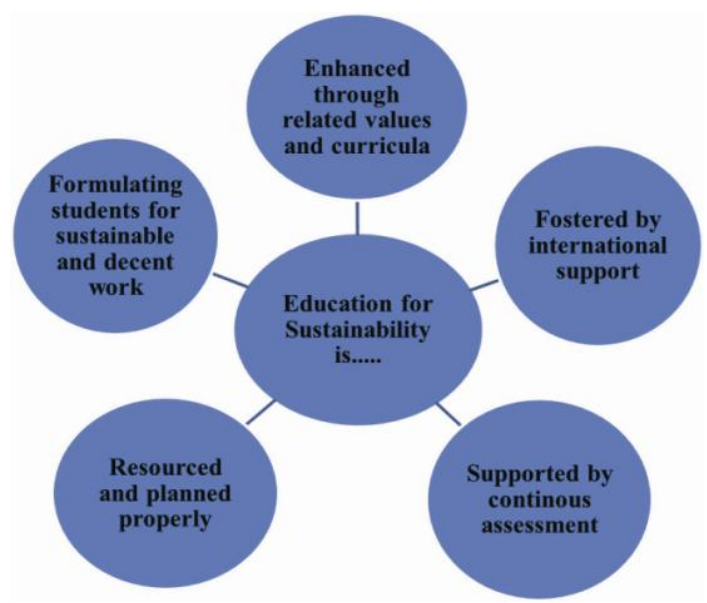

Figure 1. Education for sustainability 
Learning at all ages plays a vital role in the development of sustainable futures. At Rio+20- The United Nations Conference on Sustainable Development-countries agreed to establish an intergovernmental process to develop a set of sustainable development goals (SDGs) to help in implementing sustainable development. It was emphasized that education is fundamental in achieving sustainable development and is the most effective way to reduce poverty, but with concentrating on the quality of education, innovation in addition to lifelong learning.

Higher education is in a unique position to lead the transition process to sustainability. Universities have the means to influence students by providing these individuals- tomorrow's planners, teachers, doctors, engineers, business leaders, scientists, journalists, and politicians- the necessary skills to alter the existing societies to a sustainable cultures.

The challenge of incorporating sustainability into university curricula is significant and involves sitting on curriculum committees, developing student learning outcomes, and creating new academic programs. In addition to educating students, institutionalizing sustainability includes creating new knowledge through research and promoting sustainability through community engagement.

\section{Higher Education for Sustainable Consumption: The Concept and Importance}

Sustainable consumption requires education to be as broad as life itself; specifically, it is an approach to education that aims at incorporating learning into all activities of life and serves all individuals. The concept of lifelong learning or education during the full span of life is the most important slogan, which emerges in recent educational theory. The importance of responsible consumption choices stems from its significant effect on shaping production patterns, voting in markets and adjusting decisions made by policy makers. Higher education is one of the most important tools, which support people in making responsible choices. Higher education for sustainable consumption is essential in providing individuals with suitable information on the impacts of their daily choices as consumers (Rebello, 2003).

In other words, higher education for sustainable consumption seeks to maintain individuals with knowledge, information and skills on the environmental and social impacts of their daily choices that help them in participating in the economy and public debate and becoming actors of change towards more sustainable consumption behaviors. In addition, higher education for sustainable consumption is intended to enable students to take responsible decisions and actions, now and in the future (OECD, 2008).

Sustainable consumption is considered as an approach to decrease the negative environmental impacts from bad consumption patterns and promote quality of life for all. In addition, sustainable consumption increases the continuous and efficient management of resources and encourages the recycling of valuable resources within waste flows. In order to achieve sustainable consumption, it is necessary to have a significant cooperation and engagement among different groups; namely, policy makers, workers, consumers, retailers, researchers, media, and all other civil society organizations (González-Gaudiano, 2004).

Sustainable consumption issues should be included in higher education programs in order to help individuals in determining a proper sense of balance between their responsibilities as citizens and their rights as consumers. These programs should increase the capability of changing approaches, thoughts and values. In order to gain the benefits of such programs, they should provide understanding on the importance of particular changes and helping individuals realize a range of alternatives to find ones that make sense in their own lives. Furthermore, they should present opportunities for people to develop and practice some important skills such as multi-task performance, leadership, problem solving, managing complex functions and decision-making (González-Gaudiano, 2004).

Institutions of higher education must play a central role in the process of achieving sustainable consumption because they have specific characteristics, for example, they have expertise in science and technology; in social sciences and in all fields of research. Moreover, they have academic thinkers and huge human resources in every field of human learning. Universities and all other institutions of higher education have years of experience in teaching and training. Their research experience enables them to develop a multidisciplinary form of education suited to address the issue of sustainable consumption. Additionally, higher education institutions can help in humanizing globalization and shaping public opinion and national policies towards sustainable consumption (Rebello, 2003). At the same time, these institutions require a change in methods of education and approach of teaching and learning process. This implies that, innovative practices and experimental learning methods are required; more multidisciplinary inputs should be added to the educational content and the method of creating and exchanging knowledge should be modified (Martin \& Jucker, 2003). 


\section{What Is the Relationship between Higher Education for Sustainable Consumption and Higher Education for Sustainable Development?}

The concept of sustainable development was initially introduced at the first Earth Summit in 1972 in Stockholm. During this conference, education was introduced as an essential element in achieving sustainable development. There are many definitions of sustainable development, but the most famous one is that introduced by United Nations in 1987 as "Development which meets the needs of the current generation without compromising the ability of future generations to meet their needs". In 2005, the UN adopted a Decade of Education for Sustainable Development (DESD). The objective of the DESD is to relate the principles and values of sustainable development to all aspects of education (UNESCO, 2005). Higher education in particular is considered fundamental to the strategy for achieving sustainability because of its direct influence on graduates.

There are many attempts to implement sustainable practices into higher education institutions, for example, the Talloires Declaration, an international agreement signed by over 350 university presidents in more than 40 countries all over the world (ULSF, 1990). Other programs include the International Sustainable Campus Network (ISCN) and the Global Higher Education Sustainability Partnership (GHESP), which provide forums for institutions to exchange good practices and improve current practices.

Consumption lies at the heart of the debate about sustainable development as it covers people's right to live and work in a clean environment with good health and social conditions. However, what counts as sustainable consumption and sustainable lifestyle depends on background, environment and culture (UNEP, 2011a).

Higher education for sustainable consumption is an essential part of higher education for sustainable development. Higher education seeks to motivate the awareness of individuals and organizations and to empower them to choose responsible consumption patterns and environmentally friendly lifestyles i.e. it can make a sustained and substantial contribution to the challenge of sustainable consumption through teaching and research. Policy makers and educational authorities should give higher education the necessary resources to carry out its task in achieving a sustainable future. Accordingly, it is important to include the dimension of education for sustainable consumption in education for sustainable development (UNESCO, 2002).

Higher education plays a vital role concerning education for sustainable development and consumption and the building of a learning society (The Lüneburg Declaration on Higher Education for Sustainable Development, 2001; and Lozano et al., 2011). To achieve these roles, it needs to review and update curricula and teaching materials regularly. It perceived that, the crucial objective of education for sustainable consumption is to teach the knowledge, ethics, approaches and abilities needed to empower people to achieve sustainability (OECD, 2008).

Promoting sustainable consumption is important aspect of sustainable development, which depends on achieving long-term economic growth. Higher education is one of the most powerful tools for providing individuals with the appropriate skills and competencies to become sustainable consumers (UNESCO, 2002).

It is important to introduce sustainable consumption as part of more general consumer education. Among the guidelines for consumer education is that consumers should be able to choose healthy food, which is beneficial to their environment; to evaluate the effects of their own consumption, decisions on the environment and to practice sustainability at home (Wilsdon \& Porritt, 2000). Higher education should maintain the sustainable household consumption courses to encourage people change their consumption behaviors and to help society meet the challenge of sustainable consumption.

\section{What Are the Main Challenges of Higher Education for Sustainable Consumption?}

Universities and other institutions of higher education play an important role in achieving sustainable lifestyle choices of individuals in the society because of some reasons, for instance, universities all over the world are regarded as the centers of the most advanced knowledge. Accordingly, they should embody the methods required for the opening society through their teaching and institutional practices. In addition, they produce tomorrow's leaders and educate most of the individuals who develop and manage society's institutions and provide awareness, technologies and tools to create a sustainable future for graduates of every discipline. As a result, society expects that universities will contribute as much as possible to the solution of society's problems because of their special position (UNEP, 2010).

Higher education institutions need to address the sustainability agenda through their curriculum. This is the most important contribution to the sustainability agenda. There are a number of approaches to curricula reform, either by incorporating sustainable knowledge, skills and concepts into existing curricula or by promoting the idea of changes in the concept and processes of education and learning as a whole (Martin \& Jucker, 2003). The 
challenges facing universities in relation to the sustainability agenda are concerned with the complexity of achieving sustainability itself. This concept touches all aspects of our way of life; involves questions about human responsibility and can be seen through different perspectives and at different levels. Consequently, curriculum development based on sustainability is basically an interdisciplinary exercise. Another challenge is related to questions about purpose, content, technique and the role of professors in the institution. Professors should see themselves learners and work with uncertainty and unknown results because there is no guarantee of institutional and curriculum reform success i.e. successful changes depend on a comprehensive process. Additionally, the process of reorienting teacher training to address sustainability is an outstanding challenge facing institutions of higher education (UNESCO, 1997; and Joseph \& Peter, 2009).

Higher education should be redesigned to prepare individuals for the demands of a rapidly changing society and for highly technological changes i.e. for all aspects of life. Concerning course content, some of what is presented is fragmented and sometimes based on outdated scientific data and models that have proven to function poorly in real life. On the conceptual level, the understanding of the vision of sustainable consumption based on sustainable development is often vague. On the educational level, professors fight to combine theory and research with practice and to explain the course content within the everyday lives of their students. On the other hand, teachers come across disappointment, powerlessness and passivity of some students (Martin \& Jucker, 2003).

The challenge of how to promote and strengthen an interdisciplinary approach in university curricula and research agendas for a sustainable consumption has a different nature. This means that, there is a need to improve the processes of generating science for sustainable consumption and for more action-oriented interdisciplinary research with high spotlight on early identification of any problems and opportunities. Additionally, there is a necessity to carefully redesign effective processes of knowledge-sharing between universities, schools and other public institutions.

The central problem is not only in the entire systems or structures but also in the way people operate and think. As a result, the change has to come from the minds and inner force of the individuals. They have to be ready to cooperate in extremely elastic ways over disciplinary and institutional restrictions. Accordingly, the action plans should concentrate on actions that will have a large impact on the internal force of people. Higher education for sustainable consumption should be an instrument for ensuring awareness of consumer rights.

The change will be effective if the fundamental purposes of higher education are modified. Again, the current challenge is not only to reorient the higher education systems, but also to learn how to change the perceptions about the purpose and role of higher education towards sustainability. It can be said that, reorienting education policies and programs towards sustainable consumption include many factors, for example (UNEP, 2010):

- A balanced variety of objectives and an emphasis on citizenship education.

- Respect of human rights.

- Gender equality.

- Population and health education.

- Education for protecting and managing the natural resources depending on economic and social development.

However, without a real change in values, the technical procedures to encourage higher education for sustainable consumption will have a limited effect. This implies that, one of the most important challenges with regard to higher education for sustainable consumption is how to support plans and programs, which stimulate the individual's awareness of the central role they play in forming society and empower them to choose responsible and sustainable lifestyles (UNEP, 2011a).

Another particular challenge to higher education for sustainable consumption is globalization. Its economic and cultural impacts put a great pressure on the local methods of viewing the world. On the other hand, globalization achieves an awareness of the scale of the burdens that the society face and of ways of co-operating with others to deal with these troubles. Within some countries, higher education systems that were no longer considered adequate to meet the needs of society have been modified. For the other countries, some limited achievements have been realized like curriculum reform. Depending on the above facts, it can be said that, the challenges of higher education for sustainable consumption are difficult and complex and require long time in order to be achieved. In turn, higher education for sustainable consumption poses particular challenges to higher education institutions, planners and professors (UNEP, 2010): 
- It is necessary to develop and implement policies, rules and strategic plans on higher education for sustainable consumption more widely.

- It is important to concentrate on sending messages to governments in order to improve the process of coordination between different Ministries, for example, ministries of education, natural resources, agriculture, health, planning and environment.

- It is essential to strengthen institutional higher education capacity building and professional development processes in order to implement sustainable consumption in higher education institutions.

\section{The Implementation of Sustainable Consumption in Higher Education}

As mentioned in the previous section, the challenges of sustainable consumption in higher education institutions are difficult and complex ones. The culture of sustainability requires new partnerships among governments, professors, academic and scientific institutions and the media (Joseph \& Peter, 2009). Now, how could a management plan for the implementation of higher education for sustainable consumption be achieved?

Higher education for sustainable consumption involves action on several levels (Bartel et al., 2001):

- It consists of providing learning environments in which real actions support the goals of higher education for sustainable consumption strategies and programs.

- It is also dependent upon the systematic training of professors and the development of relevant research.

- It implies creating structural frameworks in which higher education for sustainable consumption can be achieved.

Movement towards sustainable consumption can also be developed by encouraging all institutions of higher education to provide sustainable consumption courses for a minimum number of hours per week each year. These weekly hours can either be a part of existing lectures; separate sessions in addition to existing lectures or as interdisciplinary projects. In particular, more intense learning would be expected at institutions of higher education.

Higher education for sustainable consumption is, by definition, a form of education that requires modification and updating within higher education institutions. Many of the issues that are essential today to education for sustainability were topics not imagined in the past decades. By establishing indicators of progress, implementing mechanisms for examination and sharing good practices, governments can follow and facilitate the development of higher education for sustainable consumption. Governments are supposed to make sure that higher education institutions reflect in their daily management the priorities given to sustainable consumption (UNESCO, 1998).

Changing consumption patterns is dependent on awareness of the impact of our lifestyles choices on the lives of other people around the world, acquiring an understanding of the value of services and commodities and developing skills that will help individuals become informed and responsible consumers. Higher education for sustainable consumption cannot be expected to completely transform consumption patterns but education can add significantly to the process. There are many approaches to integrate education for sustainable consumption in higher educational systems. Universities and other higher education institutions should undertake many steps to implement sustainable consumption, for instance (UNEP, 2010):

- Include degrees, topics and courses about education for sustainable consumption in established curricula.

- Improve co-operation between experts from various disciplines in order to de velop integrated approaches to education for sustainable consumption.

- Make sure that education for sustainable consumption respects the importance of original knowledge and recognizes different lifestyles.

- Support learning among different generations as an integrated aspect of education for sustainable consumption.

- $\quad$ Present opportunities for practical application of theoretical framework.

- $\quad$ Promote research in education for sustainable consumption and related areas.

- Strengthen connections between researchers, lecturers, teacher trainers and other socio-economic actors.

- Assist training programs for all teachers, administrators and educational planners to be familiar with the nature and the methods of higher education for sustainable consumption.

- Smooth the progress of teaching methods and teacher training that supports global perspectives within education for sustainable consumption. 
- Give grants to innovative thinking related to education for sustainable consumption.

Education for sustainable consumption can be treated as a topic taught as a part of existing subjects. This requires that professors clarify the relationship of education for sustainable consumption to the subject they teach and to other subjects. It means that higher education institutions need to maintain an overview of which aspects of education for sustainable consumption are covered by which subjects and when they are taught in order to ensure that education for sustainable consumption does not become fragmented (Martin \& Jucker, 2003).

Furthermore, education for sustainable consumption topics can be taught as an interdisciplinary theme and it can be incorporated in the curriculum as a particular theme, taught in particular times. These periods can be regular or concentrated in larger periods occasionally throughout the year. Subjects of this kind include life skills, global citizenship and future studies (Martin \& Jucker, 2003; and OECD, 2008).

Higher education for sustainable consumption represents a new vision of education which helps students in understanding the world in which they live, dealing with the complexity problems such as wasteful consumption, environmental degradation, population growth, gender inequality, the violation of human rights and poverty (UNEP, 2010). This vision of education gives emphasis to an interdisciplinary approach in order to develop the knowledge and skills needed for sustainable lifestyles. This requires reorientation of higher education systems, practices that empower individuals to make proper decisions and act in culturally appropriate environment (UNCED, 1992).

The most effective ways of moving forward towards higher education for sustainable consumption are; first, to identify effective plans, models and best practices for promoting higher education for sustainability and then analyze the experience in order to make recommendations based on these studies; second, to promote more effective implementation of succeeded strategies for the incorporation of sustainability in universities and other higher education institutions; third, to carry out a global assessment of progress in making sustainability of curriculum and research in higher education institutions. The success in achieving sustainability in higher education institutions includes a demonstration of commitment from senior university executive; measures to promote social and economic sustainability; successful cultural change across a university; a process for regular evaluation and reporting in order to ensure continuous and effective implementation of sustainability agendas and a development of appropriate thoughts and skills among students and professors.

As mentioned before, higher education for sustainable consumption is a complicated concept that utilizes different aspects to develop the values, skills and knowledge that will empower individuals for constructing a sustainable future. More specifically, higher education for sustainable consumption has four major mechanisms; these mechanisms were originally introduced in Section IV, Means of Implementation, Chapter 36 of Agenda 21: Promoting Education, Public Awareness and Training (UNCED, 1992; and Rebello, 2003)

- First, the promotion and improvement of high quality education by continuous updates on curricula, including the latest scientific methods of sustainability in the teaching and learning materials and conducting the scholarship and problem-based scientific research necessary to generate the new knowledge needed for sustainability.

- Second, the reorientation of existing education policies and programs through integration of different knowledge systems needed for sustainability and strengthening the interface between research findings and decision-making using evidence-based data.

- Third, the specialized training programs are needed to help individuals in creating the changes required to achieve sustainability and providing life-long learning opportunities to teachers, other professionals and all citizens.

- Fourth, the development of public understanding and awareness by encouraging and promoting all higher educational institutions to include in their activities a strong component of reflection on values with respect to sustainable consumption and promoting inter-cultural exchange of experiences in education for sustainable consumption.

\section{Conclusion}

Reorienting higher education for sustainability does not require large additional sums of money but it requires political will of governments eager to model a cooperative approach to sustainable consumption. Universities and other higher educational institutions and the community could then take up that lead to engage each individual in the process of seeking sustainable lifestyles. Achieving sustainability is the main goal; it is a goal that cannot be reached by scientific research, technological changes or by government announcement. It is a goal that requires commitment across the community as a whole, a commitment that can particularly be developed 
through higher education.

It can be said that, higher education for sustainable consumption is an interdisciplinary area under discussion that focuses on current events and conditions. Clarifying its various factors is not an easy task because the economic, social and technological circumstances of higher education for sustainable consumption change rapidly. For example, each new scientific discovery leads to the emergence of new issues. Nevertheless, this does not imply that higher education for sustainable consumption is a vague issue. With its concentration on the role of the individual, higher education for sustainable consumption deals with how each individual interacts with the society, market and environment.

Universities and other institutions of higher education must understand that they are very important actors in the process of achieving sustainability. In fulfilling this role, universities must be compared with other institutions, e.g. business, local authorities and non-governmental organizations. In particular, the interaction between business and universities is very important, because where both sectors meet, development is taking place. Consequently, universities must be perceived as partners and the participation of universities in the process of sustainability is extremely significant.

There must be awareness that different stakeholders speak different languages; universities should try to overcome this, facilitate the discussion and participate in a stakeholder dialogue in an active way. In short, the main action plans of achieving sustainable consumption in higher education include engaging with different stakeholders to create policy changes towards sustainable consumption; building the capacity of people to manage sustainable consumption; supporting the development of good practice and rewarding more sustainable behavior.

There are some key findings that are relevant to policy makers, i.e. educational authorities and policy-makers should make relevant adjustments to fit higher education for sustainable consumption in the curricula because professors are willing to include sustainable consumption in their lectures but they have no time to do so; higher education for sustainable consumption should be addressed within formal learning processes and not be confused with awareness and information activities since it implies motivation and empowerment of individuals by giving them needed values and skills. Moreover, action towards integrating education for sustainable consumption in higher education institutions should start now given that a long term process is required to influence or change education.

\section{References}

Bartel, M., Sheldon, C., \& Martin, S. (2001). The Sigma Project: Sustainability in Practice. Journal of Institution of Environmental Sciences, 10(6), 1-4.

González-Gaudiano, E. (2004). Overview of the Situation of Education for Sustainable Development in Mexico. UNU-APEC Education Network Invitation Program for Education for Sustainable Development, Yokohama, Japan, August 24-30, pp. 1-18.

Joseph, P., \& Peter, B. (2009). The Earth Charter in Higher Education for Sustainability. Journal of Education for Sustainable Development, 3(2), 151-158. http://dx.doi.org/10.1177/097340820900300210

Lozano, R., Lukman, R., Lozano, F. J., Huisingh, D., \& Lambrechts, W. (2011). Declarations for Sustainability in Higher Education: Becoming Better Leaders, through Addressing the University System. Journal of Cleaner Production, 48, 10-19. http://dx.doi.org/10.1016/j.jclepro.2011.10.006

Martin, S., \& Jucker, R. (2003). Educating Earth-Literate Leaders. Paper Presented at International Conference on Education for a Sustainable Future, Shaping the Practical Role of Higher Education for a Sustainable Development. International Association of Universities and Charles University in Prague, Charles University, Karolinum, Prague, Czech Republic, 10-11 September, pp. 1-10.

OECD. (2008). Promoting Sustainable Consumption, Good Practices in OECD Countries. Published on the responsibility of the Secretary-General of the OECD.

Rebello, D. (2003). The role for Higher Education Institutions in the UN Decade of Education for Sustainable Development. Paper Presented at International Conference on Education for a Sustainable Future, Shaping the Practical Role of Higher Education for a Sustainable Development, International Association of Universities and Charles University in Prague, Charles University, Karolinum, Prague, Czech Republic, 1011 September, pp. 1-10.

Sarabhai, K. (2015). ESD for Sustainable Development Goals (SDGs). Journal of Education for Sustainable Development, 9(2), 121-123. http://dx.doi.org/10.1177/0973408215600601 
The Lüneburg Declaration on Higher Education for Sustainable Development. (2001). The International Copernicus Conference "Higher Education for Sustainability - Towards the World Summit on Sustainable Development (Rio+10)". Held at the University of Lüneburg, Germany, 8-10 October.

ULSF (University Leaders for a Sustainable Future). (1990). Report and Declaration of the Presidents Conference.

UN (United Nations). (1987). Our Common Future. Oxford: Oxford University Press.

UN (United Nations). (2012). The Future we Want. Conference on Sustainable, Development, Rio de Janeiro, Brazil, 20-22 June 2012.

UNCED. (1992). Agenda 21. The Earth Summit: the United Nations Conference on Environment and Development, Rio de Janeiro.

UNEP. (2010). Here and Now! Education for Sustainable Consumption, Recommendations and Guidelines.

UNEP. (2011a). Visions for Change, Recommendations for Effective Policies on Sustainable Lifestyles.

UNEP. (2011b). Paving the Way for Sustainable Consumption and Production. The Marrakech Process Progress Report.

UNESCO. (1997). Educating for a Sustainable Future-A Transdiciplinary Vision for Concerted Action. Paris: UNESCO.

UNESCO. (1998). Higher Education in the Twenty-first Century: Vision and Action. World Conference on Higher Education, UNESCO, Paris.

UNESCO. (2002). Education for Sustainability, From Rio to Johannesburg: Lessons learnt from a decade of commitment. UNESCO, Paris.

UNESCO. (2005). UN Decade of Education for Sustainable Development: 2005-2014. UNESCO-Education for Sustainable Development.

Wilsdon, J., \& Porritt, J. (2000). Making Sense of Sustainability. Journal of the Institution of Environmental Sciences, 9(6), 6-9.

\section{Copyrights}

Copyright for this article is retained by the author(s), with first publication rights granted to the journal.

This is an open-access article distributed under the terms and conditions of the Creative Commons Attribution license (http://creativecommons.org/licenses/by/3.0/). 